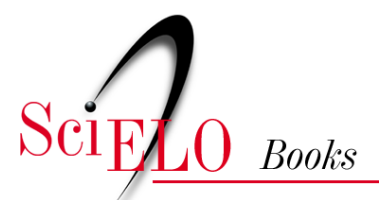

\title{
43. Rocha Lima, Embaixador da Medicina Científica Brasileira
}

\author{
Joffre Marcondes de Rezende
}

\section{SciELO Books / SciELO Livros / SciELO Libros}

REZENDE, J. M. Rocha Lima, Embaixador da Medicina Científica Brasileira. In: À sombra do plátano: crônicas de história da medicina [online]. São Paulo: Editora Unifesp, 2009, pp. 363-366. História da Medicina series, vol. 2. ISBN 978-85-61673-63-5. https://doi.org/10.7476/9788561673635.0044.

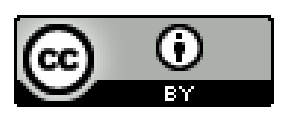

All the contents of this work, except where otherwise noted, is licensed under a Creative Commons Attribution 4.0 International license.

Todo o conteúdo deste trabalho, exceto quando houver ressalva, é publicado sob a licença Creative Commons Atribição 4.0.

Todo el contenido de esta obra, excepto donde se indique lo contrario, está bajo licencia de la licencia Creative Commons Reconocimento 4.0. 
Rocha Lima, Embaixador da Medicina Cientifica Brasileira*

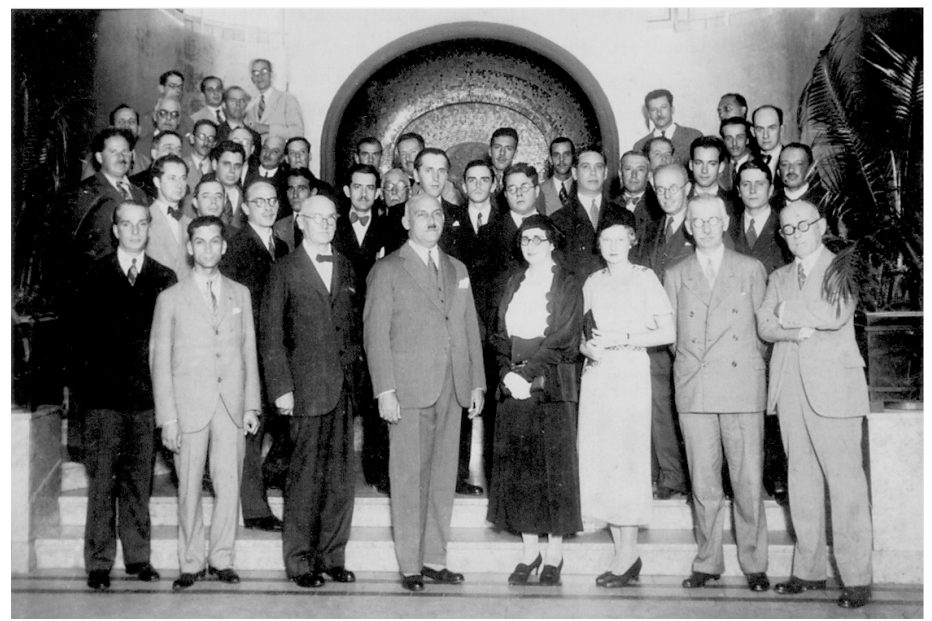

Carlota Pereira de Queiroz, ao centro. À esquerda, Rocha Lima e Alfonso Bovero, 1936.

T enrique da Rocha Lima foi o embaixador, nos países europeus, da medi1 cina científica que emergia do Instituto Oswaldo Cruz no início do século xx. Por sua genialidade, suas pesquisas e suas descobertas, projetou seu nome e, com ele, a imagem do nosso país no cenário científico internacional.

Rocha Lima nasceu em I 879, na cidade do Rio de Janeiro, onde realizou seu curso médico, concluído em I90 c com a tese Esplenomegalia nas Infecções Agudas. Ainda como estudante frequentou o Instituto Soroterápico, onde foi seduzido pelo carisma de Oswaldo Cruz conforme seu depoimento anos depois.

Em 1902 foi para a Alemanha estagiar no Instituto de Higiene de Berlim nas áreas de microbiologia e anatomia patológica.

Nesse mesmo ano, de regresso ao Brasil, foi convidado por Oswaldo Cruz para trabalhar no Instituto Soroterápico, que, em I903, passaria a chamar-se Instituto de Patologia Experimental.

* Publicado em Ética Revista, 6, pp. 26-27, 2007 
Oswaldo Cruz acumulava, então, os cargos de diretor do instituto e diretor geral da Saúde Pública e, nesse período, Rocha Lima foi um de seus principais colaboradores, inclusive na parte administrativa, substituindo-o nas suas ausências.

Em 1906 Rocha Lima voltou à Alemanha e, ciente do Congresso Internacional de Higiene e Demografia que se realizaria em Berlim no ano seguinte, sugeriu a Oswaldo Cruz a participação do instituto nesse congresso, o que se efetivou com o maior brilhantismo. A exposição do Brasil foi premiada com a medalha de ouro.

A repercussão deste evento tornou o Brasil conhecido no exterior por suas realizações em saúde pública e pesquisas científicas na área médica, com reflexos no prestígio nacional do instituto. Após sua reestruturação, em I908, passou a chamar-se Instituto Oswaldo Cruz.

Nessa ocasião, Rocha Lima dedicava-se ao estudo da febre amarela, tendo descrito lesões típicas no fígado que permitiam o diagnóstico desta enfermidade post-mortem. O quadro histopatológico por ele descrito foi posteriormente denominado "lesão de Rocha Lima" e utilizado nas viscerotomias em casos suspeitos (Bacellar, I963, pp. I80-184).

Em 1909, Rocha Lima foi convidado a ocupar o cargo de assistente na Universidade de Jena, na Alemanha, e licenciou-se do Instituto Oswaldo Cruz. Em I9Io recebeu o convite do prof. Stanislas von Prowazeki, que havia estado no Brasil e o conhecia, para trabalhar no Instituto de Moléstias Tropicais de Hamburgo, onde permaneceu como professor durante dezoito anos.

Em dezembro de I9I4 foi comissionado pelo governo alemão, juntamente com von Prowazeki, para estudar o tifo exantemático na Turquia. Von Prowazeki contaminou-se com o tifo, vindo a falecer em fevereiro de I9I 5. Rocha Lima também se infectou, porém sobreviveu.

Retornando a Hamburgo, prosseguiu com suas pesquisas sobre o tifo exantemático e, em I9 16, descobriu no intestino do piolho, o agente causador do tifo, um micro-organismo intracelular que não se enquadrava na categoria de vírus, nem de bactéria, como se acreditava. Criou, então, um novo gênero e nova espécie, a que chamou de Rickettsia prowazeki em memória de Rickets e de Prowazeki, dois cientistas vitimados pelo tifo, quando estudavam esta enfermidade. Apresentou sua descoberta ao Congresso Alemão de Medicina Interna, em I 6 de maio desse mesmo ano (Falcão, I966, pp. 55-59). 
Em I928, Rocha Lima retornou ao Brasil, acompanhando o prof. Alfons Jakob, da Universidade de Hamburgo, que vinha ministrar um curso de histopatologia do sistema nervoso no Instituto Oswaldo Cruz.

Aqui chegando, recebeu convite do governo do estado de São Paulo para ocupar o cargo de diretor da Divisão Animal do Instituto Biológico, recém-criado, que aceitou e marcou sua volta definitiva para o Brasil. Tem início, então, uma nova fase na vida de Rocha Lima.

Em 1933 assumiu a direção do Instituto, em substituição a Arthur Neiva. Sob sua gestão imprimiu ao instituto um ritmo de trabalho a que estava acostumado na Alemanha e fez do instituto a modelar instituição que tantos benefícios trouxe ao desenvolvimento, em bases científicas, da agricultura e da pecuária do estado de São Paulo e do país (Rebouças, 2006, pp. 995-I005).

A importância da descoberta do agente causal do tifo exantemático, de certo modo ofuscou suas muitas outras pesquisas relativas à doença de Chagas, febre amarela, histoplasmose, carbúnculo, e outras rickettsioses.

Rocha Lima recebeu muitas honrarias, tais como a Cruz de Ferro da Primeira Guerra Mundial, medalha de mérito do Papa Pio XI, medalha Notch do Instituto de Moléstias Tropicais de Hamburgo, insígnia da Cruz Vermelha Alemã e o título de Cavaleiro do Governo Alemão, além de outras (Bacellar, op. cit.).

Nem tudo, entretanto, foram alegrias em sua carreira, que foi pontilhada por algumas frustrações. A primeira delas refere-se à sua descoberta das lesões hepáticas características da febre amarela. O seu valor não foi reconhecido pelos seus próprios colegas do Instituto Oswaldo Cruz, que a elas se referiam como sendo de Councilman. Somente em I928, por ocasião de um surto epidêmico de febre amarela no Rio de Janeiro, a Comissão Rockefeller, sob a direção de F. Soper, restabeleceu sua autoria e demonstrou o seu valor no diagnóstico anatomopatológico da febre amarela (Ramos, s.d.).

Outra frustração diz respeito à sua descoberta da Rickettsia prowazeki. No mesmo ano em que comunicou sua descoberta, realizou-se em Varsóvia um congresso cujo tema oficial era exatamente a etiologia do tifo exantemático. Estavam inscritos Rocha Lima e H. Topfer, um médico militar que havia investigado o tifo exantemático em Vloclawek, na Polônia. Embora no programa figurasse o trabalho de Rocha Lima em primeiro lugar, coube a Topfer fazer antes sua comunicação. A Rocha Lima foi permitido apresentar somente um pequeno resumo, sem projeções ilustrativas de sua documentação. 
Indignado, Rocha Lima dirigiu uma carta ao presidente do congresso, solicitando a retirada de seu trabalho. Os organizadores do congresso, no entanto, decidiram publicar na íntegra a comunicação de Rocha Lima (Falcão, op. cit.).

A maior decepção viria posteriormente, quando, em I 928 , foi conferido o prêmio Nobel de Fisiologia e Medicina a Charles Nicolle por haver descoberto o transmissor do tifo exantemático, que é o piolho. Nicolle admitia que o micro-organismo responsável pela doença fosse um vírus filtrável (Cannon, I99I, pp. 287-294).

Seria de justiça que Rocha Lima partilhasse o prêmio com Nicolle ou que recebesse o prêmio em outro ano, como se deu no caso da malária, em que Ronald Ross recebera o prêmio em I902 por sua descoberta do mosquito transmissor da malária, e Alphonse Laveran em I907, pela identificação do plasmódio.

Tal como aconteceu com Carlos Chagas e a descoberta da tripanossomíase americana, o Brasil foi mais uma vez prejudicado pelos critérios variáveis de julgamento da Fundação Nobel.

Rocha Lima faleceu em I956, aos 76 anos. Sua vida e sua obra foram uma grande lição para as futuras gerações de pesquisadores de nosso país.

\section{Referências Bibliográficas}

Bacellar, R. C. Brazil's Contribution to Tropical Medicine and Malaria. Rio de Janeiro, Gráfica Olimpica Editora, I963.

Cannon, B. D. "Charles Nicolle I928”. In Magill, F. N. The Nobel Prize Winners. Physiology or Medicine. Pasadena, Salem Press, I99I.

Falcão E. C, "Henrique da Rocha Lima e a Descoberta da Rickettsia prowazeki". Revista do Instituto de Medicina Tropical de São Paulo, 8 (2), pp. 52-59, 966.

Ramos, M. “Rocha Lima, o Pai das Rickettsias”. Invivo, Fiocruz. Disponível em http:// www.invivo.fiocruz.br/cgi/cgilua.exe/sys/start.htm?sid=6, acesso em 28 ago. 2009.

Rebouças, M. M. "Pelo Resgate da Memória Documental das Ciências e da Agricultura: o Acervo do Instituto Biológico de São Paulo”. História, Ciências, Saúde - Manguinhos, I3 (4), pp. 995-1005, 2006. 